\title{
The Influence of the Geometrical Properties of Bulk Superconductors on Limiting Fault Current in an Electrical Network
}

\author{
Salah Belkhiri' ${ }^{1}$,otfi Alloui², Fethi Ben Mebarek², \\ ${ }^{1}$ Department of Electrical Engineering, Faculty of technology, University of M'Sila, Algeria \\ ${ }^{2}$ Department of Electrical Engineering, Faculty of technology, University of Biskra, Algeria \\ *corresponding author, E-mail: salah.belkhiri@univ-msila.dz
}

\begin{abstract}
The behavior of the superconducting fault current limiters SFCL used in Electrical Network is largely determined by the geometry properties and the type of the bulk superconductors used. In this work we present a numerical analysis of the electromagnetic and the thermal behavior of the SFCL and the influence of geometrical properties of the bulk superconductors of rectangular shape used in an electrical network The results are obtained from a threedimensional computation code, developed and implemented under MATLAB environment where the formulation in magnetic vector potentials A and electrical scalar potential $\mathrm{V}$ are adopted to solve the electromagnetic problem and the heat diffusion formulation is also adopted to solve the thermal problem. The coupling is ensured by an alternating algorithm and the numerical resolution of the problem is ensured by the method of the finite volumes in its threedimensional version in order to avoid certain problems of numerical convergence linked to the strongly nonlinear character of the problem to be solved.
\end{abstract}

\section{Introduction}

The use of fault current limiters designed from superconducting materials of high critical temperature has made it possible to limit the fault currents in the electrical networks. In the event of a short circuit, the latter must not only be able to withstand this fault regime and act as natural current regulators, but also reduce the mechanical and thermal stresses experienced by the network [1].

These limiters offer the advantage on the one hand, to be invisible in the rated or rated speed and to be able to limit the fault currents in a very short response time compared to conventional current limiters or conventional circuit breakers [2]. These advantages, which are specifically offered by current limiters designed from high critical temperature superconductors, have led to their insertion with large suctions in medium and high voltage power grids [3]. It is not possible during a test to try all the possible configurations of short-circuit on a network, according to the type of network (overhead or underground), according to the impedance of the fault, and according to the power of the network. It is therefore interesting to have modeling tools to simulate the behavior of a superconducting current limiter and to extrapolate the results obtained to other short-circuit configurations and to other network voltage levels. In this context, several simulation works have been proposed. In some of these works, the behavior of the superconductor is simulated as a vary-resistance [2], [5-6] where the superconducting material changes from non-dissipative state characterized by zero resistance in the rated regime of the network to a non-dissipative state. Very dissipative state characterized by a high resistance in the case of faults that can appear during the operation of the electrical network [15-16-17]. These simple models developed do not satisfactorily reflect the actual behavior of the superconductor in its intermediate state, particularly the FLUX-FLOW and FLUX CREEP regimes. For this, other microscopic models have been proposed in order to satisfactorily describe the FLUX-FLOW and FLUX CREEP regimes [4], [9]. In these models, the Maxwell equations are adopted and coupled to the heat diffusion equation, however the electromagnetic and thermal problems are solved in the case of one-dimensional [7] see bi-dimensional [8]. These models cannot properly simulate superconducting current limiters, typically of type II. For this, we propose in this paper a three-dimensional mathematical-numerical model dedicated mainly to the modeling of fault current limiters. This model presents the results of the simulations of the magnetic and thermal behavior of the superconducting current limiter before and during the process of limitation.

\section{Formulation}

To model the magnetic behavior of the presented problem, we adopted the formulation in magnetic vector potentials $\mathrm{A}$ and in electric scalar potential V, this one is described by the formulation below.

$$
\begin{aligned}
& \nabla \times(v \nabla \times \mathrm{A})-\nabla(v \nabla \cdot \mathrm{A})+\sigma(E, T)\left(\frac{\partial \mathrm{A}}{\partial \mathrm{t}}+\nabla V\right)=\mathrm{J}_{\mathrm{s}} \\
& \nabla \cdot\left\{-\sigma(E, T)\left(\frac{\partial \mathrm{A}}{\partial \mathrm{t}}+\nabla V\right)\right\}=0
\end{aligned}
$$


$v$ and $\sigma$ represent respectively the magnetic reluctivity and the electrical conductivity of the superconductor. Concerning the apparent electrical conductivity of the superconducting material, in its non-dissipative state, it is defined by the ratio of $\mathrm{J}$ on $\mathrm{E}$ [11] and [12], this ratio is deduced from the characteristic E-J of the superconductor given by the relation.

$$
\begin{aligned}
& \sigma_{S}(E, T)=\frac{J}{E}=\frac{J_{c}(T)}{E_{c}}\left(\frac{E}{E_{c}}\right)^{\frac{1}{n(T)}-1} \\
& \text { With } J_{c}(T)=J_{c 0} \frac{\left(1-\frac{T}{T_{c}}\right)}{\left(1-\frac{T_{0}}{T_{c}}\right)}
\end{aligned}
$$

This relation reflects the superconductors Flux-Flow and Flux-Creep regimes that is to say if the superconductor is in a non-dissipative state, to complete the expression of the electrical conductivity of the superconductor in the dissipative regime. Add an additional term $\sigma_{\mathrm{ng}}$ which translates the increase in the resistance of the superconductor. Thus, the apparent electrical conductivity of the superconductor is deduced by the relation.

$$
\sigma(E, T)=\sigma_{s}(E, T)+\sigma_{n}(T)
$$

Where $J_{C}$ and $E_{C}$ respectively represent the density of the critical current and the critical electric field. According to relation (3), the apparent conductivity of the superconductor depends on the electric field $\mathrm{E}$ and the temperature $\mathrm{T}$ reached within the material. The electric field $\mathrm{E}$ will be determined from the resolution of the electromagnetic problem described by the partial differential equation presented by the formulation (1). The temperature will be determined from the resolution of the heat diffusion problem presented by

$$
\rho C_{p}(T) \frac{\partial T}{\partial t}-\nabla .(\kappa(T) \nabla T)=W
$$

Where $\lambda(T), \quad \rho, \quad C p(T)$ are respectively the thermal conductivity in $(\mathrm{W} / \mathrm{K} / \mathrm{m})$, the density in $(\mathrm{Kg} / \mathrm{m} 3)$ and the specific heat of the material in $(\mathrm{J} / \mathrm{K} / \mathrm{Kg}), \mathrm{W}$ is a power density in ( $\mathrm{W} / \mathrm{m} 3)$, it expresses all the losses generated in the superconducting current limiter expressed by

$$
W=E . J
$$

In the results of the simulations presented, the thermal and the electrical properties depend on the temperature as mentioned in the equations (1), (2), (3), (4). The Models describing this dependence are presented in [14].

The resolution of the system of equations 1 and 4 solves electromagnetic and thermal problems. These are defined by strongly nonlinear equations. To solve such a problem, several methods have been used mainly finite element method [4-9], it can not ensure the convergence of the problem to be solved especially during the presence of a superconducting material where have used a power type law to define electrical conductivity (Equation 2). To avoid this type of problem we used the finite volume method in its three-dimensional version. [13][14]. the adopted mesh is of Cartesian or structured type, it consists of elementary volumes of hexahedral or cubic form. For each volume Dp of hexahedral shape, we associate a so-called main node $\mathrm{P}$ and six facets: $\mathrm{e}$ and $\mathrm{w}$ in the direction $\mathrm{x}, \mathrm{n}$ and $\mathrm{s}$ in the direction $\mathrm{y}, \mathrm{t}$ and $\mathrm{b}$ in the $\mathrm{z}$ direction (Fig.2). The neighboring volumes of $\mathrm{Dp}$ are represented by their close neighboring nodes: $\mathrm{E}$ and $\mathrm{W}$ along the $\mathrm{x}, \mathrm{N}$ and $\mathrm{S}$ axis along the $\mathrm{y}, \mathrm{T}$ and $\mathrm{B}$ axis along the $\mathrm{z}$ axis $[13,14]$.

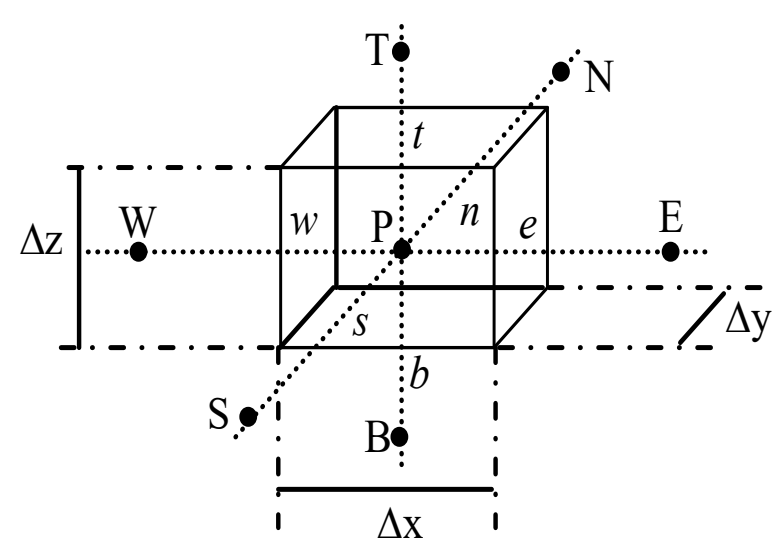

Figure 1: Elementary finished volume

$$
\begin{aligned}
& \iiint_{D_{P}} \nabla \times(v \nabla \times A) d \tau-\iiint_{D_{P}} \nabla(v \nabla \cdot A) d \tau+\iiint_{D_{P}} \sigma\left(\frac{\partial A}{\partial t}+\nabla V\right) d \tau=\iiint_{D_{P}} J_{s} d \tau \\
& \iiint_{D_{P}} \nabla \cdot\left\{-\sigma\left(\frac{\partial A}{\partial t}+\nabla V\right)\right\} d \tau=0
\end{aligned}
$$

$$
\begin{aligned}
& \int_{w}^{e} \int_{s}^{n} \int_{b}^{t} \rho C_{p} \frac{\partial T}{\partial t} d \tau= \\
& \int_{w}^{e} \int_{s}^{n} \int_{b}^{t} \frac{\partial}{\partial x}\left(\kappa \frac{\partial T}{\partial x}\right) d \tau+\int_{w}^{e} \int_{s}^{n} \int_{b}^{t} \frac{\partial}{\partial y}\left(\kappa \frac{\partial T}{\partial y}\right) d \tau+\int_{w}^{e} \int_{s}^{n} \int_{b}^{t} \frac{\partial}{\partial z}\left(\kappa \frac{\partial T}{\partial z}\right) d \tau+\int_{w s}^{e} \int_{s}^{n} \int_{b}^{t} W d \tau
\end{aligned}
$$

To calculate the derivative terms in (6) and (7), we consider in our study a linear variation of the magnetic potential and the temperature across the integration facets of the finite volume. After integration, we arrive at a system of 
algebraic equation below that will be solved by an algebraic method such as the Gauss-Seidel method that will be adopted in our problem. The integral of equations (6) and (7) leads to the following algebraic equations [13-14]:

$c p A_{x}^{P}+\sigma_{p} D_{p} A_{x}^{\bullet P}=$
$\left[\sum_{m=e, w \ldots} c_{m} A_{x}^{M}+\sum_{\substack{i=y, z \\ m=e, w \ldots}} q_{m} A_{i}^{M}+\frac{\sigma_{p} D_{p}}{\Delta x_{e}+\Delta x_{w}}\left(V^{E}-V^{W}\right)+J_{s x} D_{p}\right]_{(8)}$

$c p A_{z}^{P}+\sigma_{p} D_{p} A_{z}^{\bullet P}=$

$\left[\sum_{m=e, w \ldots} c_{m} A_{z}^{M}+\sum_{\substack{i=x, y \\ m=e, w \ldots}} q_{m} A_{i}^{M}+\frac{\sigma_{p} D_{p}}{\Delta z_{t}+\Delta z_{b}}\left(V^{T}-V^{B}\right)+J_{s z} D_{p}\right]_{(9)}$

$V^{P}=\frac{1}{u_{p}}\left[\sum_{m=e, w \ldots} u_{m} V^{M}+\sum_{\substack{i=x, y, z \\ m=e, n \ldots}} c v_{m} A_{i}^{\bullet M}\right]$

$[C][\dot{T}]+[K][T]=[Q]$

The electromagnetic and thermal coupling is ensured by the alternating coupling model.

\section{Presentation of simulation parameters}

The basic principle of the current limiter involves the properties of $\mathrm{YBaCuO}$ [10-11] which vary considerably depending on the temperature. $\mathrm{YBaCuO}$ is a superconductor having a critical temperature $\mathrm{T}_{\mathrm{C}}$ of the order of $92 \mathrm{~K}$.

This part sets up the choices made on the materials and properties that will be used for the simulations that will follow. Figure 2 shows the description of the pellet model.

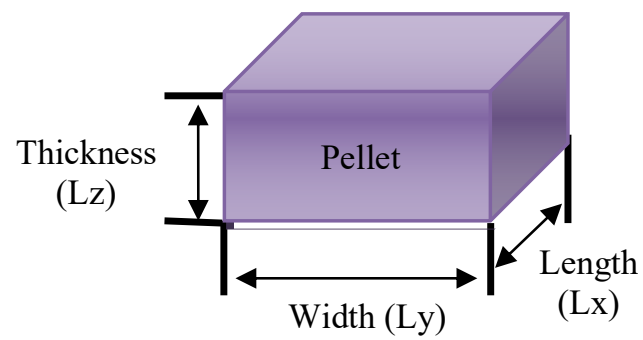

Figure 2: The description of the pellet model.
The following tables gather the geometrical parameters and characteristics of the material studied YBCO by our simulation code.

Table 1: Geometrical properties of bulk superconductors used in our simulations.

\begin{tabular}{cccc}
\hline $\begin{array}{c}\text { Size of the bulk } \\
\text { superconductors }\end{array}$ & $\begin{array}{c}\text { Lx } \\
{[\mathrm{mm}]}\end{array}$ & $\begin{array}{c}\text { Ly } \\
{[\mathrm{mm}]}\end{array}$ & $\begin{array}{c}\mathrm{Lz} \\
{[\mathrm{mm}]}\end{array}$ \\
\hline Type A & 4 & 4 & 4 \\
Type B & 6 & 6 & 6 \\
Type C & 8 & 8 & 8 \\
Type D & 10 & 10 & 10 \\
\hline
\end{tabular}

Table 2: Parameters of the $\mathrm{YBaCuO}$ bulk.

\begin{tabular}{|c|c|c|}
\hline Symbol & Quantity & value \\
\hline Tc & $\begin{array}{c}\text { Critical } \\
\text { temperature }\end{array}$ & $92 \mathrm{~K}$ \\
\hline $\mathrm{T}_{0}$ & $\begin{array}{c}\text { Coolant } \\
\text { temperature }\end{array}$ & $77 \mathrm{~K}$ \\
\hline Ec & & $1 \times 10^{-4} \mathrm{~V} / \mathrm{m}$ \\
\hline $\mathrm{Jc}$ & $\begin{array}{l}\text { Critical electric } \\
\text { field } \\
\text { Critical current } \\
\text { density at } 92 \mathrm{~K}\end{array}$ & $5 \times 10^{7} \mathrm{~A} / \mathrm{m}^{2}$ \\
\hline $\mathrm{n}_{0}$ & $\begin{array}{c}\text { Exponent } \mathrm{n} \text { at } \\
77 \mathrm{~K} \text { under } \\
\text { zero field }\end{array}$ & 20 \\
\hline Icc & $\begin{array}{l}\text { Maximum } \\
\text { short-circuit } \\
\text { current }\end{array}$ & $16 \mathrm{KA}$ \\
\hline
\end{tabular}

\section{Numerical results and discussion}

In this first simulation part, it is considered that the current limiter is essentially formed by different superconducting pellets, it is the transition by overflow of the critical current that initiates the transition that must be fast enough to effectively limit the current and be homogeneous so as not to damage the pellet.

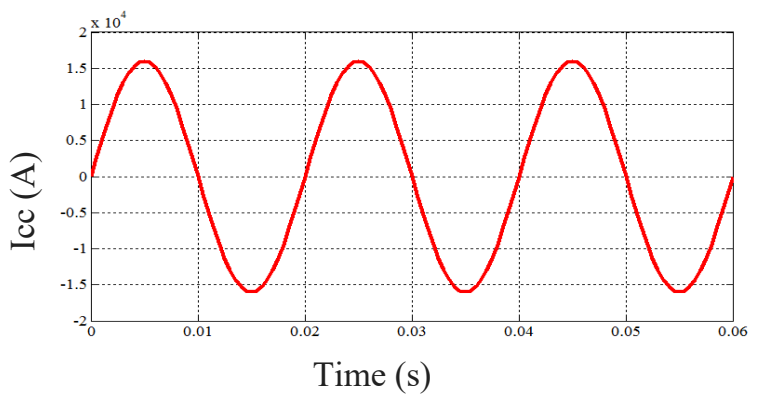

Figure 3: Waveform of the applied short-circuits current. 
4.1. Spatial distribution of the density of the current $\mathbf{J}$ within the superconducting pellets
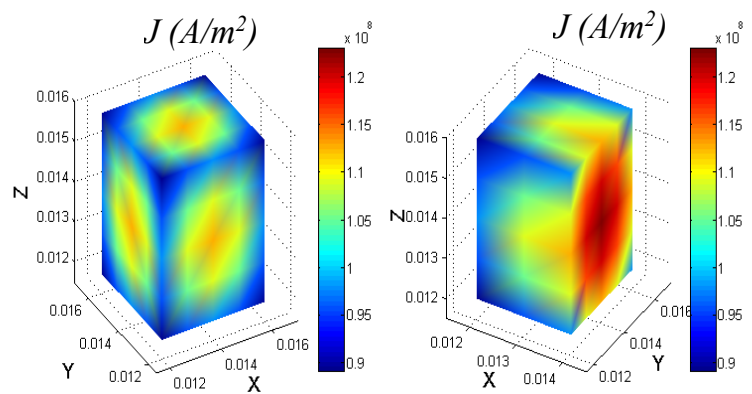

Figure 4: Current density distribution of the $\mathrm{J}$ in the pellet A at $\mathrm{t}=0.06 \mathrm{~S}$.
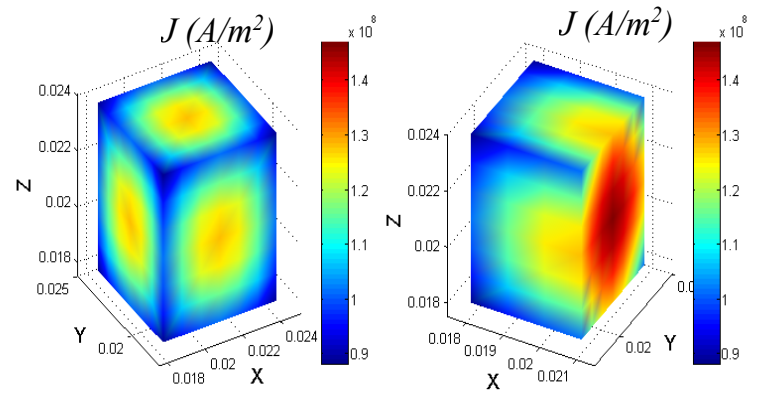

(a)
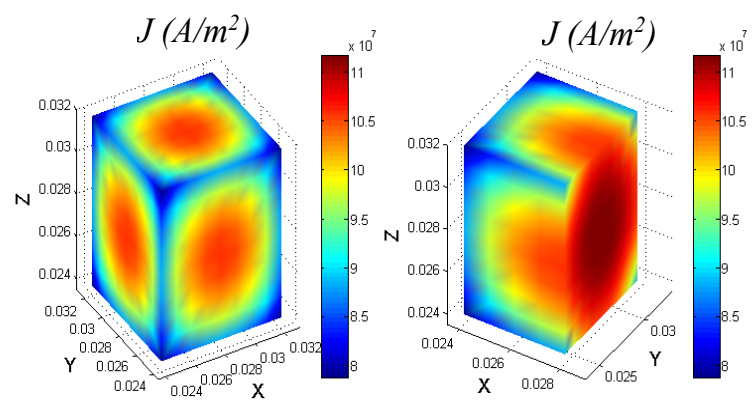

(b)

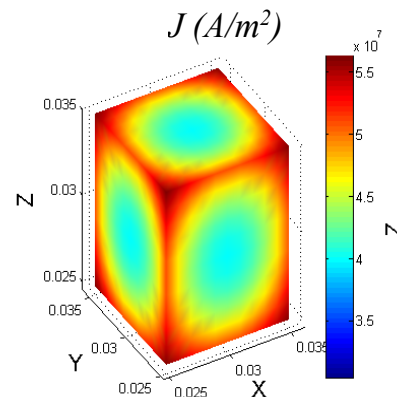

$\mathrm{Y}(\mathrm{m}) \underbrace{0.025}_{\mathrm{X}(\mathrm{m})}$

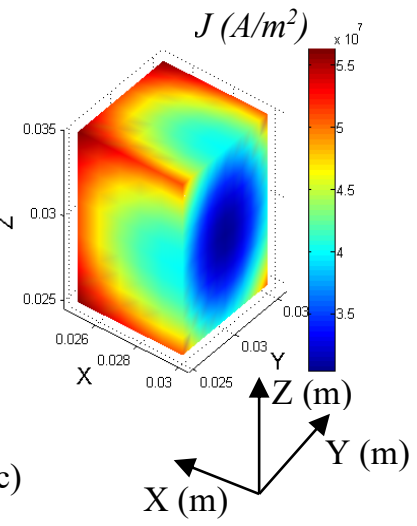

Figures 4, (a), (b) and (c) illustrate the spatial distribution of the currents in the superconducting pellets at time $\mathrm{t}=0.06 \mathrm{~s}$, given that their critical current density is considered $\mathrm{Jc}=5$ $\times 107 \mathrm{~A} / \mathrm{m} 2$. It appears from these results, that the current density reaches its maximum with a high concentration in the center of the pellets $\mathrm{A}, \mathrm{B}$ and $\mathrm{C}$, in contrast in the pellet $\mathrm{D}$ the phenomenon is not identical, the current density is concentrated stronger in the peripheries of the latter, this is explained by the fact of its size.

The choice of the value of the critical density Jc of the superconducting pellets has a decisive influence on the temporal variation of the current density in the latter.

For this reason, we have shown in Figure 6 the results of simulation of the variation of the ratio $\mathrm{J} / \mathrm{Jc}$ as a function of time for different values of $\mathrm{Jc}$, respectively for $\mathrm{Jc}=$ ( $5,6,7,8,9) \times 107 \mathrm{~A} / \mathrm{m} 2$ in the pellet $\mathrm{A}$.

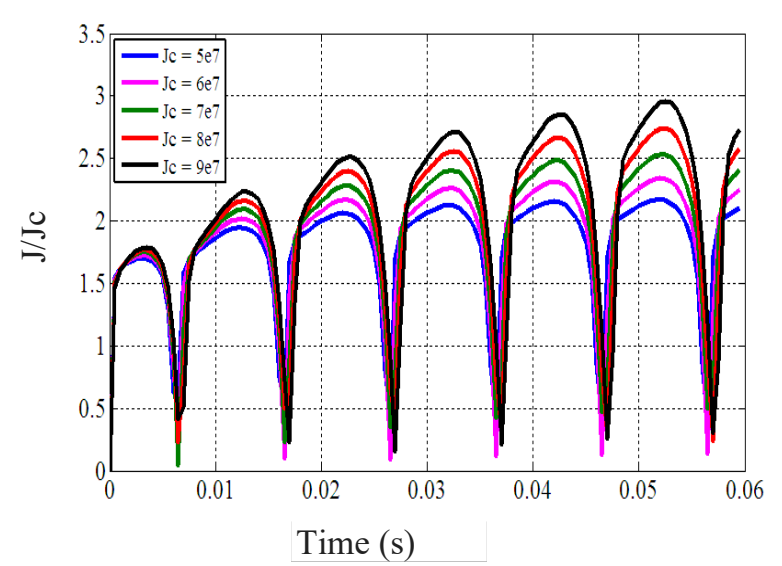

Figure 6: The variation of the ratio $\mathrm{J} / \mathrm{Jc}$ of the pellet A for different values of $\mathrm{Jc}$ as a function of time.

There are significant differences in the variation of this ratio as a function of time [10].

The figure 7 shows the variation of the $\mathrm{J} / \mathrm{Jc}$ ratio for the different superconducting pellets $\mathrm{A}, \mathrm{B}, \mathrm{C}$ and $\mathrm{D}$ as a function of time with $\mathrm{Jc}=9 \times 107 \mathrm{~A} / \mathrm{m} 2$. It is clear that for this rate of $\mathrm{Jc}$, the superconducting limiter intervenes faster in a very short time even before the short circuit current reaches its maximum during the first half cycle. It also appears that the chip A is more advantageous and has given more performance of a desired superconducting limiter. The advantage of a thin layer is its very fast transition; the current is limited for a $\mathrm{J} / \mathrm{Jc}$ ratio generally less than two. It is thus a very efficient material for the limitation of the short circuit current.

Figures 5: Current density distribution of the $\mathrm{J}$ at $\mathrm{t}=0.06 \mathrm{~S}$ (a) Pellet B, (b) Pellet C and (c) Pellet D. 


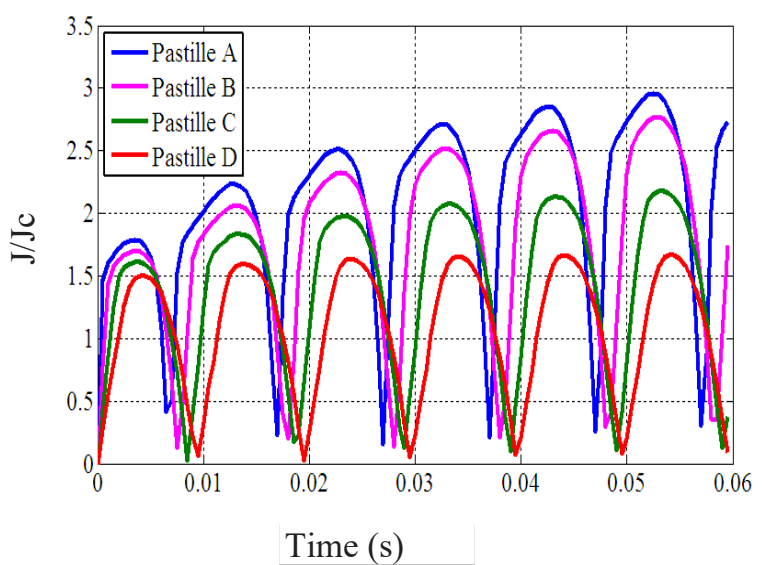

Figure 7: The variation of the $\mathrm{J} / \mathrm{Jc}$ ratio for the different superconducting pellets $\mathrm{A}, \mathrm{B}, \mathrm{C}$ and $\mathrm{D}$ as a function of time with $\mathrm{Jc}=9 \times 107 \mathrm{~A} / \mathrm{m} 2$

There are significant differences in the variation of this ratio as a function of time this is mainly due to different sizes of the selected superconducting pellets. In addition, a significant increase in the temporal variation of the current density in the pellets $\mathrm{A}$ and $\mathrm{B}$, but with less growth for the pellets $\mathrm{C}$ and $\mathrm{D}$. Which means, that for $\mathrm{Jc}=9 \times 107 \mathrm{~A} / \mathrm{m} 2$, the ratio $\mathrm{J} / \mathrm{Jc}$ increases considerably during the first half of the value substantially equal to 1.8 to a value of about 3 in the sixth alternation for the pellet $\mathrm{A}$ and 1.7 to 2.8 for the pellet $B$, In the pellet $C$ and $D$, this ratio takes the values of 1.6 to 2.3 and 1.5 to 1.7 , respectively, from the first alternation to the sixth alternation.

\subsection{Spatial distribution of temperature $T$ within the superconducting pellets}

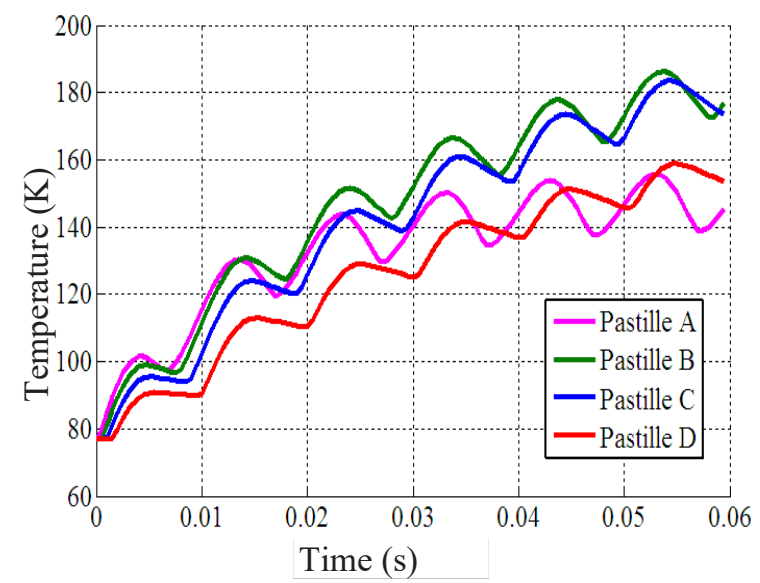

Figure 8: The variation of the temperature in the different pellets as a function of time.
Figure 8 shows and summarizes the temporal evolution of the temperature in the different pellets. From these results, it can be seen that at time $t=1 \mathrm{~ms}$, the limiter keeps its superconductive state whatever the pellet used, because the temperatures recorded are all lower than Tc. On the other hand, the transition time of the limiter was carried out respectively at times $\mathrm{t}=2,5 \mathrm{~ms}, \mathrm{t}=3,5 \mathrm{~ms}, \mathrm{t}=4,5$ $\mathrm{ms}$ and $\mathrm{t}=11 \mathrm{~ms}$ (see Table 3 ). It is clear that the smaller the size of the pellet, the shorter the intervention time of the limiter. It is also noted that the temperature within the pastille varied not only with time but also with the choice of the size of the pellet.

Table3: The transition time from the superconducting state to the normal state for the various superconducting pellets.

\begin{tabular}{cc}
\hline pellets & Transition time $[\mathrm{ms}]$ \\
\hline A & 2.5 \\
B & $3 ; 5$ \\
C & 4,5 \\
D & 11 \\
\hline
\end{tabular}

In order to show the influence of the length Lx of the pellet on the thermal behavior of a current limiter, we calculated the spatial distribution of the temperature within the superconducting pellet for the different values of $\mathrm{Lx}$ and for a Constant Jc $(\mathrm{Jc}=5 \times 107 \mathrm{~A} / \mathrm{m} 2)$ (see Table 4).

Table 4: The different values of Lx

\begin{tabular}{|c|c|c|c|c|}
\hline Pellets & A & B & C & D \\
\hline \multirow{2}{*}{ Length } & 04 & 06 & 08 & 10 \\
\cline { 2 - 5 } Lx en (mm) & 06 & 09 & 12 & 15 \\
\cline { 2 - 5 } & 08 & 12 & 16 & 20 \\
\cline { 2 - 5 } & 10 & 15 & 20 & 25 \\
\hline
\end{tabular}

4.3. The influence of the geometry of the superconducting pellet on the thermal behavior of a current limiter

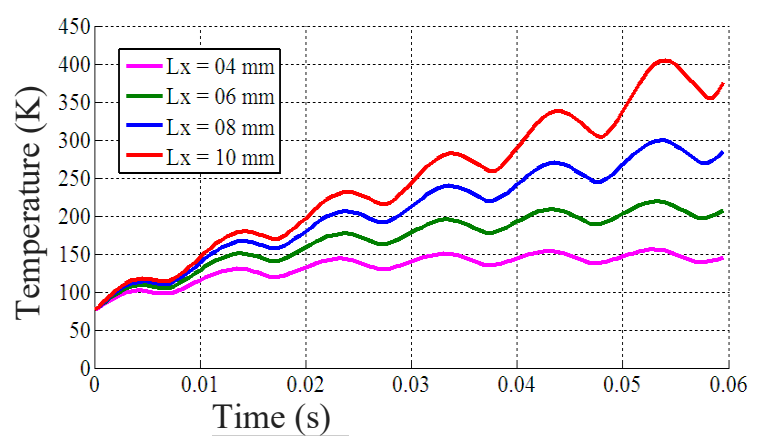

(a) 


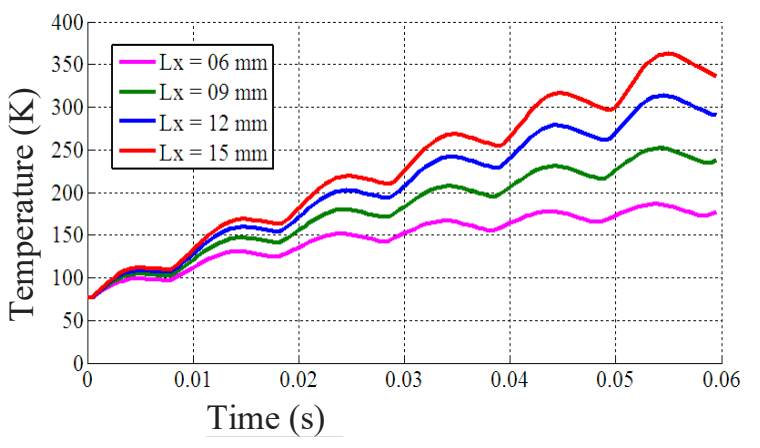

(b)

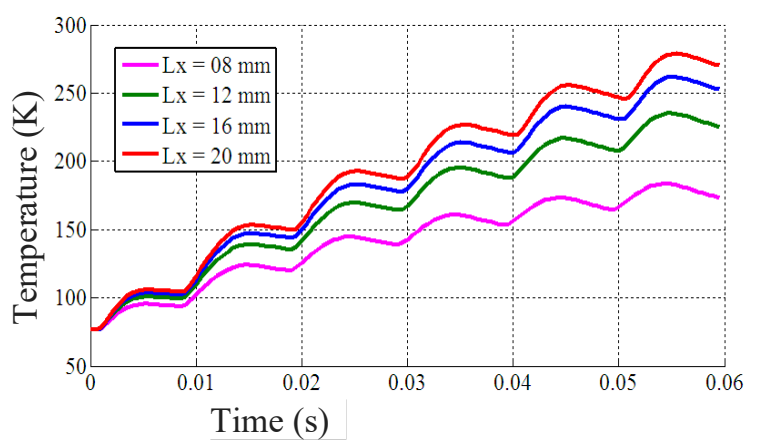

(c)

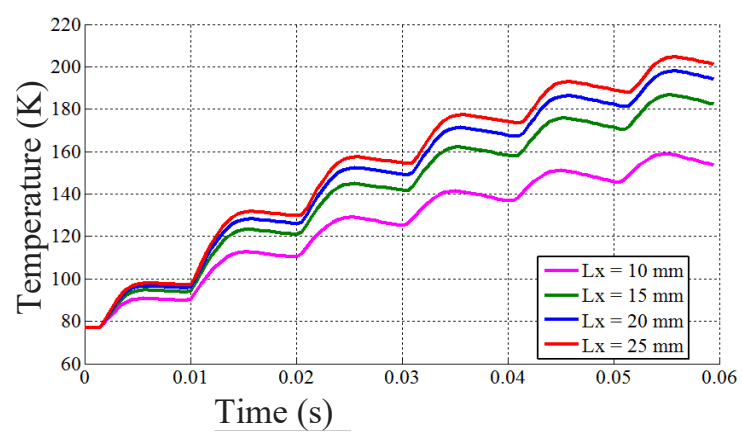

(d)

Figure 9: The variation of the temperature as a function of time for variable $\mathrm{Lx}$. in the different pellets respectively (a), pellet A, (b) pellet $\mathbf{B}$, (c) pellet $\mathbf{C}$ and (d) pellet $\mathbf{D}$.

We notice the rapid rise in temperature with increasing length Lx. The maximum of this temperature, which corresponds to the region where the losses are significant, varies proportionally from one value of length to another and from one pellet to another. In addition, the temporal evolution of these temperatures then makes it possible to record the moments of intervention of the limiter, that is to say (the transition from its superconductive state to its normal state). This transition is caused by exceeding the critical temperature.
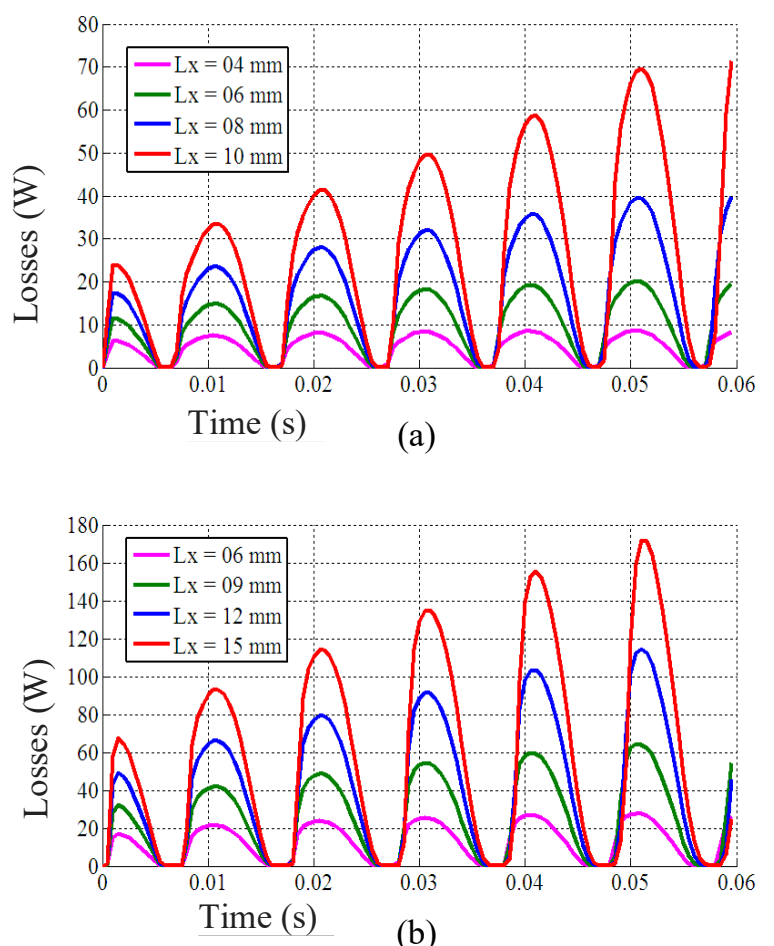

(b)
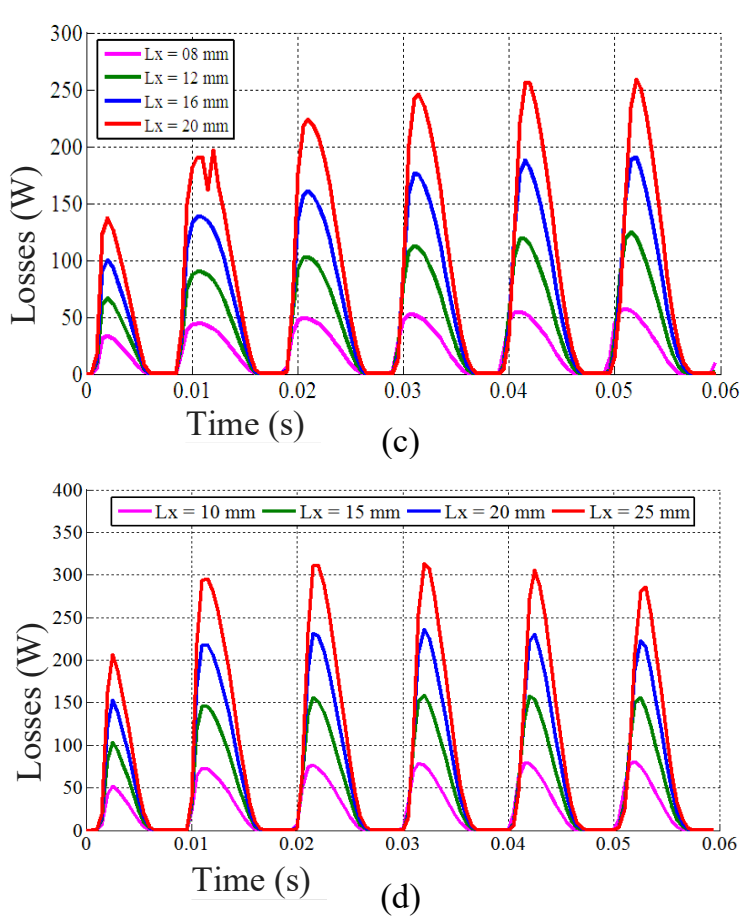

Figure 10: Losses variation as a function of $\mathrm{Lx}$ in the different pellet respectively (a) pellet $\mathbf{A}$, (b) pellet $\mathbf{B}$, (c) pellet $\mathbf{C}$ and (d) pellet $\mathbf{D}$.

According to the results obtained, there appears to be a significant increase in these average losses as a function of the length Lx chosen. This is essentially translated by the particular geometry of the pellet, with very different dimensions. In addition, a high energy density that will dissipate inside the pellet. 


\section{Conclusions}

After several simulations, a study was carried out in terms of transition time, the distribution of the density of the current and the temperature in the breasts of the pellets. An expression of the variation of the SFCL impedance due to the presence of the short-circuit current has also been established while explaining the geometric and electromagnetic characteristics of the SFCL (modification of the matrix admittance of the system). In order to simulation an SFCL, it is necessary to understand the transition from the superconducting state to the normal state. This transition open the advantage on the one hand, to be invisible in the rated speed and to be able to limit the fault currents in a very short response time (under $05 \mathrm{~ms}$ ) compared to conventional current limiters or conventional circuit breakers (50 to 80 $\mathrm{ms}$ ) [10].The simulation results obtained by pellets A, B and $\mathrm{C}$ are very satisfactory.

\section{Acknowledgements}

The author wishes to thank Prof. L. ALLOUI and Mr F. B. MEBAREK for their valuable contributions.

\section{References}

[1] Y. Cointe, Doctorat Thesis, "Continuous superconductive limiter," Engineering Sciences [physics]. National Polytechnic Institute of Grenoble INPG, 2007. French. <Tel-00300552>.

[2] N. Saad, Doctorat Thesis, University of Setif, "Modeling and simulation of the superconducting current limiter," 2013.

[3] H. Kado and M. Ichikawa, "Performance of a high-Tc superconducting fault current limiter - design of a $6.6 \mathrm{kV}$ magnetic shielding type superconducting fault current limiter," IEEE Trans. Appl. Supercond., vol. 07, no. 2, pp. 993-996, June. 1997.

[4] W. K. Chan and al, "Three-dimensional micrometerscale modeling of quenching in high-aspectratioYBa $2 \mathrm{Cu} 3 \mathrm{O} 7-\delta$ coated conductor tapes-part I: model development and validation," IEEE Trans. Appl. Supercond., vol. 20, no. 6, pp. 2370-2379, December. 2010.

[5] J. B. Na and al, "Design and tests of prototype hybrid superconducting fault current limiter with fast switch," IEEE Trans. Appl. Supercond., vol. 22, no. 3, pp. 5602604, June. 2012.

[6] H. Yamaguchi and all, "Current limiting characteristics of transformer type superconducting fault current limiter with shunt impedance," IEEE Trans. Appl. Supercond, vol. 17, no. 2, pp. 1919-1922, June. 2007.

[7] K. Nam and al, "Thermal and electrical analysis of coated conductor under AC over-current," IEEE Trans. Appl. Supercond, vol. 17, no. 2, pp. 1923-1926, June. 2007.

[8] C. and al, "Two-dimensional anisotropic model of YBCO coated conductors," IEEE Trans. Appl. Supercond., vol. 25, no. 1, pp. 6600112, February. 2015.
[9] W. K. Chan and al, "Three-dimensional micrometerscale modeling of quenching in high-aspectratioYBa2 $\mathrm{Cu} 3 \mathrm{O} 7-\delta$ coated conductor tapes-part II: influence of geometric and material properties and implications for conductor engineering and magnet design," IEEE Trans. Appl. Supercond., vol. 21, no. 6, pp. 2628-2634, June. 2011.

[10]O. Belmont, "Current limitation based on superconducting oxides and realization of a 100 A-1 KV," Device. Ph.D, National Polytechnic Institute of Grenoble - INPG, 1999. French. <tel-00763892>.

[11] Y. Yoshida, M. Uesaka, and K. Miya, "Magnetic field and force analysis of high Tc superconductor with flux flow and creep,' IEEE Trans. Magn, vol. 30, no. 5, pp. 3503-3506, September. 1994.

[12] T. Fujioka. "3-D analysis of current distribution and AC loss induced by external AC magnetic field in multifilamentary superconducting wires,' IEEE Trans on Magntics, vol. 32, no. 3, pp. 1140-1143, May. 1996.

[13] L. Alloui, F. Bouillault, S.M. Mimoune., '’3D modeling of forces between magnet and HTS in a levitation system using new approach of the control volume method based on an unstructured grid," Physica C 475 32-37, 2012.

[14]L. Alloui, F. Bouillault, S. M. Mimoune, "Numerical study of the influence of flux creep and of thermal effect on dynamic behaviour of magnetic levitation systems with a high-Tc superconductor using control volume method," EPJ. App. Phys., Vol. 37, No. 2, pp. 191-195, February. 2009.

[15] J, Zhu. X. Zheng, M. Qiu, Z. Zhang, J. Li, W. Yuan, "Application simulation of a resistive superconducting fault current limiter (SFCL) in a transmission and wind power system," Science Direct Energy Procedia 75 716-721, 2015.

[16]B. Mahdad, K. Srairi, "Application of a combined superconducting fault current limiter and STATCOM to enhancement of power system transient stability," Physica C 495 160-168, 2013.

[17] W.T.B. d. Souse, A. Polasek, F. A. Silva, R. Dias, A. R. Jurelo, R. d. Andrade, Jr. 'Simulation and tests of MCP-BSCCO-2212 superconducting fault current limiters,' IEEE Trans. Appl. Supercond., vol. 22, no. 2, 6pp. 5600106, April. 2012. 